We have prepared a set of Study Helps for High School Students and have arranged for their sale at cost through the Michigan Education Association (Lansing). We have not copyrighted this material and schools have been informed that they may reprint the Study Helps.

\title{
STUDY HELPS FOR HIGH-SCHOOL STUDENTS
}

Arranged by Inspector J. B. Edmonson, University of Michigan, and Assistant Superintendent C. L. Goodrich, Department of Public Instruction

1. Be certain that you prepare the correct assignment in scope, content, and form. Consider such questions as: What readings, problems, experiments, or topics were assigned? Was part or all of the preparation to be written? What dangers, difficulties, or important points were emphasized by the teacher in making the assignment? Which of these study helps did the teacher urge students to follow?

2. Have a study program. Budget your time so as to have a definite time and a definite place to prepare each lesson.

(The teacher will explain how to make a study program card.)

3. Have proper study conditions and needed materials-a quiet room not too warm, plenty of light at your left, a straight chair, a table, the necessary dictionaries, rulers, pencils, and other materials.

4. Make careful preparation of advanced assignment as soon as possible after a class, but allow time in your study program for review of essential points before going to class.

5. Do your studying with vigor and determination. Work while you work. When actually tired, change your work, take exercise, or go to sleep. One must be rested in order to study effectively.

6. Learn to do two kinds of reading. Read rapidly when seeking to find major points or to make a survey of a lesson. Read cautiously and critically such material as problems, directions, explanations, and any material that must be interpreted or mastered. Never read rapidly when you should read cautiously. Acquire the habit of analyzing confusing statements. To test the efficiency of your reading and to guard against "skimming" or "day dreaming," pause at the end of 
paragraphs or natural units and seek to recall the gist of what you have read.

7. Avoid acquiring the habit of half mastery. In committing material to memory learn it as a whole. Do not learn piece-meal. Keep going over the material until you have it letter perfect. In learning rules, forms, poems, dates, vocabularies, etc., it is helpful to repeat them aloud especially if you are expected to give them orally in class. (The teachers will explain the mistake of memorizing material that should be analyzed and understood.)

8. Hunt for key words, phrases, or sentences; and mastcr the full meaning of these. Write them on a slip of paper for later review.

9. Work indcpendently. Ask for help only after you have exhausted your own resources. Cultivate self-reliance, determination, and independence in work. Pride yourself on your ability to get your lesson done.

10. Frame questions to test your preparation of a lcsson and use these questions to measure your preparation before going to class.

11. Attempt to answer to yoursclf every question that is asked in class and thus review, test, and drill yourself on essential facts. (Teachers will seek to conduct their classes so as to stimulate you to do this.)

12. Strive to excel. Do not be contented to "get by." Convince yoursclf of the genuine value of doing your bost work in cach of your studies. Be honest in all work. Be able to answer such a question as: Why is the subject worth studying? (Your teachers will seek to emphasize the invaluable character of the information or training in each study.)

The foregoing Study Helps are based on the contributions of authorities and writers in the field of the psychology of learning. The rules do not, therefore, represent any original contributions of the authors. Some recent writers have very vigorously attacked the contents of certain of the sets of study helps for high-school pupils, and have pointed out that the giving of rules to pupils will accomplish little. You will find that Monroe $^{1}$ declares that study helps are certainly a "far cry" from the elaborate plans for the immediate direction

${ }^{1}$ Monroe, Directing Learning in the High School, p. 413. 
of study called for in other schemes. I fully agree with the criticisms of certain of the sets of study helps. It is a mistake to assume that pupils will be able to take a set of rules and apply them efficiently without much assistance from the teacher. In the set of study helps that has been prepared for Michigan schools, special care has been taken to emphasize the responsibility of the teacher in the training of pupils. This is well illustrated in the first one of the study helps, where questions are included to define the responsibility of the teacher in the making of an assignment. Again the responsibility of the teacher is emphasized in the second item relating to a study program where the statement is included, "The teacher will explain how to make a study program card." In other paragraphs you will find similar reference to the responsibility of the teacher. If your teachers prepare a set of study helps or guides to be placed in the hands of the pupils of your school, may I urge that you insist that the type of service that a teacher should render to a pupil be made an essential part of the statement.

Step 4. Printed copies of the study holps should be distributed to the pupils through their classroom teachers and the pupils directed to paste a copy in each of their textbooks.

Step 4 is a very necessary step in order to insure the united efforts of all teachers. I urge this step because of the tendency of some teachers to neglect to contribute their part to the training of pupils in habits of study. Unless Step 4 is emphasized by the principal, a few of the teachers in a school will become the "trainers" of pupils in effective habits of work while the others will continue to be the "testers" of preparation. If pupils are to be effectively trained, all of the teachers in a given school must be both "trainers" and "testers."

Step 5 . The teachers should be directed to take at least ton minutes of each recitation at frequent intervals to teach the pupils how to apply the different study suggestions to their subjects.

I wish to warn principals that the distribution of study helps to pupils will accomplish very little unless the teachers observe Step 5. Pupils need specific instruction in how to apply rules of study just as much as athletes need specific instruction in good form in running, jumping, or swimming. Whipple ${ }^{1}$ has stated the reason for Step

\footnotetext{
${ }^{1}$ Whipple, How to Study Effectizely (rev. ed.), p. 9.
} 
5 when he says, "To bring these rules to the attention of high-school or college students and have them understand them is, accordingly, not difficult. But to have them apply the rules to the actual process of studying a given subject is quite another thing. Furthermore, to apply a rule correctly to the actual studying of a subject under the direction and guidance of the teacher is one thing, and to use the same rule daily, without being directed to do so, is quite another thing."

As principals you know that it is easy to acquaint pupils with the rules for effective studying but it is a real and difficult task to cause pupils to cultivate habits of effective studying. It should be every teacher's business to see to it that the rules are applied in the work going on under his directions. A principal should give special attention to the practices of his teachers in showing pupils how to apply certain rules of study.

Step 6. Teachers should use the study helps as a guide in seeking the causes for the failure of individual pupils.

Teachers should use the study helps as a guide in seeking the causes for the failure of individual pupils. I know of no more effective way to arouse in teachers a desire to discover the real difficulties of pupils than to insist upon Step 6. It is also an excellent way for a teacher to measure the effectiveness of his own instruction in habits of study. I wish to urge that principals refuse to be satisfied with the traditional explanations of pupil failures and insist that teachers use diagnostic aids in discovering real causes. Many teachers are handicapped by insufficient training in the use of diagnostic instruments. Such deficiencies in preparation can be readily overcome through the study of a number of excellent books on pupil measurement and guidance. A principal should take advantage of the presence in his school of failing pupils to stimulate his teachers to become more expert in discovering and removing the learning difficulties of pupils.

Step 7. Teachers should be encouraged to derise supplementary sets of suggestions to be used by pupils in the study of particular subjects-e.g., algcbra, Latin. (For suggestions consult references 4 and 6.)

It is needless to argue the necessity of Step 7. While it is true that certain rules of study are equally applicable to all subjects, the 
fact, nevertheless, remains that pupils need different directions for work in Latin than they need for work in some field of English or mathematics. Teachers will find specific suggestions for different subjects in a recent publication. ${ }^{1}$

Step 8. A copy of the study helps should be mailed to the parents of each pupil with a letter urging coöperation in carrying out rules 2, 3, 5, and 9 of the Michigan list.

I do not mean to convey the idea, by proposing Step 8, that parents should be held responsible for training pupils in effective habits of study. It must be apparent, however, that certain of the items in the study helps cannot be observed without active coöperation of the school and the home. The necessity for encouraging parents to create more favorable conditions at home for study is very effectively set forth in a poem by Edgar A. Guest, entitled, "Temptations of Youth." A reading of this poem will convince one that Guest knows the difficulties that pupils encounter in home study. He says in part-

"I may tell him that I studied through the winter evenings long, That I proved my tough examples till I knew that none was wrong; But when I was reading Cæsar by the lamplight's mellow glow, The room was always quiet, for we had no radio.

Now the nights are filled with music, and the air is full of song, There's a prize fight in the parlor. You can hear the ringside gong, You can hear the crowds applauding as the battle is begun, And I wonder that a youngster ever gets his homework done."

The majority of high-school pupils must do a certain amount of studying at home or risk low marks. In view of this it seems to me that principals should seek to instruct parents concerning home conditions that are most favorable.

Step 9. A copy of the study helps should be printed in the local newspaper with the same explanation of the importance of the problem.

In view of the fact that many parents believe that the high school is neglecting to train pupils in effective habits of work, I would strongly recommend that some attention be given to acquainting the public with efforts made to improve the quality of training in habits of study. Unless this is done, the public will continue to voice criticisms. As a

${ }^{1}$ Teuton, Suggestions for Effective Study in Secondary Schools. 
part of his public relations program a principal should give the public some information concerning his program for training pupils in habits of study. I think there is a further reason for printing the study helps in the local paper, which is to be found in the desire that many people possess, outside of school, to improve their own habits of study.

Step 10. Teachers should be urged to take an experimental attitude toward the undertaking, and should at frequent intervals be required to make an inventory of results.

This last step is proposed because it is extremely important to encourage teachers to take an experimental point of view towards the problem of training pupils in habits of study. It is highly desirable to cause them to feel that the problem is not one that lends itself to an easy solution. It is, therefore, a problem on which all classroom teachers may make some valuable contribution. It is, in my opinion, a mistake to introduce any plan for training pupils in habits of study in such a way as to suggest to teachers that the proposed plan is a "cure all," and that if it fails the teachers are to blame. If Step 10 is followed, teachers will from time to time be called upon to pool their opinions and their findings relative to the changes that have been taking place in the study habits of the pupils. Such an invoice of results is quite certain to reveal some elements of strength and other elements of weakness in the program that has been set up in the school.

The question may be raised by some, Do we need a program for a given school or may we safely leave this problem to the individual teachers? It is my own observation that a specific program is needed. Many of the teachers are not prepared to work out procedures of their own for the training of pupils in habits of study. Other teachers will say as one of the teachers of my own state said to me this past year, "I am so busy trying to cover the outline of my course that I do not have time to train pupils in habits of study." In turn there are many habits of study that can only be developed and strengthened through united emphasis on the part of all the teachers. I have also found in my inspection of high schools that where the problem was left to the teachers, only a small minority of the teachers were giving any attention to the problem.

In view of the helpful material now available in books and bulletins, there is little excuse for a school failing to work out a plan for 
training pupils in habits of study. The plan outlined in the foregoing paragraphs may be followed with modifications, or a school may develop an entirely different procedure. It is presented in order to get a program before you. What appears to be most needed, however, is a more positive conviction on the part of principals that it is part of their responsibility to insure that teachers train their pupils in effective habits of work. To do this requires the constant and vigorous efforts of the principals.

Professor of Education, W. Carson Ryan, Jr., of Swarthmore College, Pennsylvania, read his paper, Selection as a Function of American Secondary Education.

\section{SELECTION AS A FUNCTION OF AMERICAN SECOND- ARY EDUCATION}

W. Carson Ryan, Jr.,

Professor of Education, Swarthmore College,

Swarth more, Pennsylvania.

One who speaks on the selective function of American secondary education at the present juncture is under peculiar obligation to state promptly and unequivocally where he stands on the American public high school and its expansion. Let me say at the outset, therefore, that I believe in this expansion; that I regard the ideal of highschool education or the equivalent for every boy and girl as not only feasible, but essential. We who are concerned with American education must not allow ourselves to be diverted from this goal of universal secondary schooling by the wails of those who complain on principle, in terms of "sanctified squander," about expenditures for public education. We must not be diverted from our goal by the comparatively few of the private secondary school group who for commercial or social reasons resent the expansion of good secondaryschool facilities at public expense; by the few remaining university presidents, chiefly in the East, who do not understand and apparently do not intend to understand the philosophy of American public education; by those who honestly but mistakenly confuse the older European goals with our present ones; or by that minority among American industrialists-I am convinced it is really a minority- 